\title{
Doença renal crônica e estado nutricional
}

\author{
Chronic kidney disease and nutritional status
}

\author{
Ana Elizabeth P. L. Figueiredo \\ Professora Titular da Faculdade de Enfermagem, Nutrição e Fisioterapia e do Programa de Pós-Graduação em Medicina e Ciências da Saúde da
} Pontifícia Universidade Católica do Rio Grande do Sul, Porto Alegre, RS.

DESCRITORES: DOENÇA RENAL CRÔNICA; HEMODIÁLISE; NUTRIÇÃO; EQUIPE INTERDISCIPLINAR DE SAÚDE.

KEY WORDS: CHRONIC KIDNEY DISEASE; HEMODIALYSIS; NUTRITION; INTERDISCIPLINARY HEALTH TEAM.

A doença renal crônica (DRC) é uma epidemia mundial, especialmente em países em desenvolvimento. Em 2004, no Brasil, foi instituída a Política Nacional de Atenção ao Portador de Doença Renal, a ser implantada em todas as unidades federadas, respeitadas as competências das três esferas de gestão: atenção básica, de média e de alta complexidade. O Censo da Sociedade Brasileira de Nefrologia de 2012 estimou uma população em diálise de quase 100 mil pacientes, sendo que $90 \%$ destes estão em hemodiálise, e consomem cerca de $1 \%$ do orçamento da saúde no tratamento da DRC. ${ }^{1}$ Um terço dos pacientes em diálise no Brasil estão acima dos 65 anos, faixa etária em que as limitações de ordem física aumentam, associadas a múltiplas comorbidades. À fragmentação e complexidade do tratamento desses pacientes, associa-se o prognóstico reservado da DRC. ${ }^{2}$

Sabe-se que a DRC em estágio terminal impõe restrições às atividades da vida diária do paciente, como esquema terapêutico rigoroso, que provoca modificações alimentares, convívio com doença irreversível, limitações das atividades sociais e de trabalho, utilização de vários medicamentos, dependência de uma máquina e alterações da imagem corporal. Neste cenário, o trabalho da equipe multiprofissional, formada por médicos, enfermeiros, nutricionistas, assistentes sociais, psicólogos, técnicos de enfermagem e profissionais envolvidos na manutenção dos equipamentos, é de suma importância para garantir a saúde e o bem estar desses doentes.
Neste número da Scientia Medica, dois artigos abordam aspectos nutricionais de pacientes em hemodiálise: um deles avalia o estado nutricional e fatores associados, enquanto o outro investiga a relação do estado inflamatório com a massa magra corporal. Barros et al. ${ }^{3}$ demonstram associação entre estado inflamatório e idade, achado preocupante frente à realidade cada vez maior de pacientes idosos em hemodiálise. No estudo de Dobner et al. ${ }^{4}$ houve elevada prevalência de excesso de peso pelo índice de massa corporal, mas depleção nutricional nas demais variáveis antropométricas, além de diminuição da albumina a valores abaixo do ideal. Estes achados podem estar associados às restrições impostas na alimentação dos pacientes em hemodiálise por DRC, seja pela própria limitação das atividades da vida diária, seja pela inflamação e outras alterações fisiopatológicas da uremia.

A preocupação com o estado nutricional é tanta, que a Portaria $n^{\circ} 389$ do Ministério da Saúde, publicada em março de 2014, que define os critérios para a organização da linha de cuidado da pessoa com DRC pelo Sistema Único de Saúde, determina, como um dos indicadores de qualidade do programa, que a proporção de pacientes em tratamento dialítico com albumina sérica acima de 3,0 mg/dl deve ser maior do que $70 \%$ ao final de dois anos após a implementação da política. Nesse importante documento também é assegurado ao paciente o direito de receber, sob orientação do nutricionista e/ou por prescrição médica, aporte 
nutricional no dia do tratamento, o que talvez minimize as alterações nutricionais encontradas nessa população, as quais podem influir na sua morbimortalidade. ${ }^{5}$

Em conjunto, o apoio da equipe multidisciplinar e a educação para hábitos mais saudáveis podem aumentar a capacidade do paciente para enfrentar a doença, melhorando sua motivação em aderir às intervenções terapêuticas e de estilo de vida necessárias. ${ }^{6}$ As estratégias da equipe multidisciplinar devem ser dirigidas às necessidades dos pacientes e devem se adaptar aos recursos do sistema de saúde de cada país; a implementação sistemática desses programas pode contribuir para a melhora nos cuidados às pessoas com DRC.

\section{REFERÊNCIAS}

1. Sesso R, Lopes AA, Thomé FS, Lugon JR, Watanabe Y. Relatório do Censo Brasileiro de diálise Crônica 2012. J Bras Nefrol. 2014;36(1): $48-53$.

2. Martínez-Ramírez HR, Cortés-Sanabria L, Rojas-Campos E, Hernández-Herrera A,Cueto-Manzano AM. Multidisciplinary strategies in the management of early chronic kidney disease. Arch Med Res. 2013;44(8):611-5.

3. Barros A, Sussela AB, Felix R, Lucas LSilveira, d'Avila DO. Pacientes em hemodiálise: estado inflamatório e massa magra corporal Sci Med. 2014;24(1):6-10.

4. Dobner T, Trevizan CT, Pomatti G, Pasqualotti A, Bettinelli LA. Avaliação do estado nutricional em pacientes renais crônicos em hemodiálise Sci Med. 2014;24(1):11-8.

5. Brasil. Ministério da Saúde. Portaria $n^{\circ}$ 389, de 13 de março de 2014. Diário Oficial da União. 2014;CLI(50):34-37. [Citado em abril de 2014]. Disponível em: <http://pesquisa.in.gov.br/imprensa/jsp/visualiza/index.jsp?data=14/03/2014\&jornal=1\&pagina=34\&total Arquivos $=164>$.

6. Chen YR, Yang Y, Wang SC, Chiu PF, Chou WY, Lin CY, Chang JM, Chen TW, Ferng SH, Lin CL. Effectiveness of multidisciplinary care for chronic kidney disease in Taiwan: a 3-year prospective cohort study. Nephrol Dial Transplant. 2013;28(3):671-82. 6 